International Journal of Maternal and Child Health and AIDS (2020), Volume 9, Issue I, I6I-I66

\begin{tabular}{ll}
\hline & INTERNATIONAL JOURNAL of \\
& MATERNAL and CHILD HEALTH and AIDS \\
& ISSN 216I-864X (Online) \\
& ISSN 216I-8674 (Print) \\
IJMA Available online at www.mchandaids.org & DOI: 10.21 I 06 /ijma.348 \\
\hline
\end{tabular}

ORIGINALARTICLE

\title{
Paternal Involvement and Adverse Birth Outcomes in South Gujarat, India
}

\author{
Nupur B. Godbole, MD;' Megan S. Moberg, MD; ${ }^{2}$ Parth Patel, MD; Jayesh Kosambiya, MD; ${ }^{3}$ \\ Hamisu M. Salihu, MD, PhD; ${ }^{5}$ Elba Adriana Campos, MPH; ${ }^{6}$ Lynette Menezes, PhD;7 Ragini Verma, MD; ${ }^{8}$ \\ Ronee Wilson, $\mathrm{PhD}, \mathrm{MPH}^{9 凶}$ \\ 'Morsani College of Medicine, University of South Florida, Tampa, FL, USA; ${ }^{2}$ Morsani College of Medicine, University of South Florida, Tampa, FL, USA; \\ ${ }^{3}$ Morsani College of Medicine, University of South Florida, Tampa, FL, USA; ${ }^{4}$ Department of P\&SM, Medical College New Civil Hospital, Surat, India; \\ ${ }^{5}$ Baylor College of Medicine, Department of Family and Community Medicine, 370I Kirby Drive, MS: BCM700, Houston, TX 77098, USA; ${ }^{6}$ Department of \\ Epidemiology and Biostatistics, College of Public Health, University of South Florida, Tampa, FL, USA; ${ }^{7}$ Department of Internal Medicine, Morsani College \\ of Medicine, University of South Florida, Tampa, FL, USA; ${ }^{8}$ Department of OBGYN, Medical College New Civil Hospital, Surat, India; ' $L a w t o n$ and Rhea \\ Chiles Center for Healthy Mothers and Babies, College of Public Health, University of South Florida, Tampa, FL, USA \\ Corresponding author email: rwilson2@health.usf.edu
}

\section{ABSTRACT}

Background and Objectives: While the impact of maternal factors on birth outcomes are widely reported, the extent to which paternal involvement and varying cultural family dynamics influence birth outcomes particularly in an international context, remain understudied. The purpose of this study was to assess the relationship between paternal involvement and adverse birth outcomes in South Gujarat, India.

Methods: An in-person questionnaire was administered to adult women at delivery or during the one-month postpartum visit at New Civil Hospital, in South Gujarat, India between May and June 2016 to assess level of paternal support and attendance at prenatal appointments and household structure. Pregnancy variables including birthweight and gestational age at delivery were collected from maternal and newborn record/chart review. Chi-square and t-test were used to assess demographics, as appropriate. Logistic regression was used to examine the association between paternal involvement and pregnancy birth outcomes.

Results: Of the 404 infants born during the study period, $26.7 \%$ were premature ( $<37$ weeks gestation) and $29 \%$ were of low birth weight $(<2500 \mathrm{~g})$. More than $40 \%$ of the women surveyed reported their in-laws were the primary household decision-makers; however, those who reported high paternal attendance were less likely to report in-laws as the primary decision-maker $(p=0.03)$. Adjusted logistic regression analysis indicated the odds of delivering a low birth weight infant were greater among mothers who reported low paternal support and low paternal attendance at prenatal visits $(\mathrm{OR}=2.99$ (95\% Confidence Interval $(\mathrm{Cl})$ : I.84-4.86) and OR=2.16 (95\% Cl: I.35-3.47), respectively).

Conclusion And Global Health Implications: Low paternal support during pregnancy may be a missed opportunity to increase healthy practices during pregnancy as well as decrease the risks associated with limited social support during pregnancy. It is important to consider varying socio-cultural family dynamics in different populations and how they may influence paternal involvement during pregnancy.

Key words: • Paternal involvement • Paternal support • Pregnancy complications • Low birth weight - Preterm birth

Copyright (C) 2020 Godbole et al. Published by Global Health and Education Projects, Inc. This is an open-access article distributed under the terms of the Creative Commons Attribution License CC BY 4.0. 


\section{Introduction}

\section{I. Background of the Study}

The health of a nation is often defined by its infant mortality rate. The 2008 National Family Health Survey conducted in India reported infant mortality to be $4 \mathrm{I}$ per I,000 live births.' Compared to other middle-income countries, India's rate is concerning. ${ }^{2}$ While the impact of maternal factors on birth outcomes are globally reported, the extent to which paternal involvement influences birth outcomes remains poorly understood.' Paternal involvement and birth outcomes have shown at least a moderate level of association ${ }^{5}$ in the United States. ${ }^{5}$ Studies have examined paternal age, ${ }^{3}$ financial contributions, paternity acknowledgment, ${ }^{4}$ and overall paternal involvement in relation to birth outcomes. ${ }^{5}$

In international settings, such as India, paternal involvement could be an important factor affecting birth outcomes, and identifying this is a significant step towards optimizing healthcare delivery to children and women.' However, few studies have explored the relationship between paternal involvement and different cultural family dynamics and infant outcomes. These studies have primarly focused on the association between paternal involvement and antenatal or childcare utlization and have not explored the influence of paternal involvement or factors influencing paternal involvement on birth outcomes. ${ }^{6,7,8}$ In many countries where extended households are common, the household power is not divided solely between a husband and wife. Specifically in India, the extended household includes at least the wife, husband, and the wife's in-laws. ${ }^{9,10,11,12}$ India's different socio-cultural norms and traditions compared to western countries may cause different household dynamics impacting paternal involvement and consequently birth outcomes.

In the socio-cultural aspect of Indian household dynamics, mothers-in-law have a unique set of influences. The presence of a mother-in-law as a figure of power in a household may alter the balance of power between a husband and a wife. Treatment of wives differ throughout India. In the North, women are traditionally less-valued than their male counterparts 9,12 and therefore, mothers-in-law may hold their son's needs at higher importance than the needs of their daughter-in-law.

\section{I.2. Objectives of the Study}

The objective of this study was to assess the relationship between paternal involvement and family dynamics on birth outcomes such as low birth weight or weighing less than 2500 grams) and premature delivery or being born less than 37 weeks of gestation. Partner/paternal support was assessed using an 8-item Likert scale and family dynamics were assessed by inquiring about the primary decision-maker in the household. It was hypothesized that low paternal support and low paternal attendance at prenatal appointments will be associated with increased odds of women delivering infants too early (premature) or too small (low birth weight).

\section{Methods}

This cross-sectional study was conducted in South Gujarat, India, between May and July 2016. Inclusion criteria were adult women (I 8 years of age and older) in South Gujarat, and surrounding areas, who had delivered within the Gujarat Medical College of Surat and New Civil Hospital within the study timeframe. Women were interviewed during their postpartum stay or at the one-month postpartum visits.

\section{I. Study Variables}

Data were collected through a questionnaire that included medical and social history, in addition to information about prenatal visits and factors that facilitated or deterred prenatal visits. Detailed questions were also asked about the father's contributions to the pregnancy as it related to accompaniment to prenatal visits, knowledge about pregnancy, time spent together with spouse during pregnancy, and willingness to support spouse during pregnancy. Questions regarding partner support were adapted from an 8-item Likert scale which assesses constructs ranging from financial support to emotional support. ${ }^{13}$ To assess paternal support, scores (ranging from 4-strongly agree to I-strongly disagree) for all 8 items were totalled and the median was used to assess a cut-point for high paternal support and low paternal support. Similarly, the median was used to determine high paternal attendance and low paternal attendance. Additionally, women were asked to determine the primary decision-maker of their household as either their in-laws, their husbands, 
themselves, or equally distributed household power. Maternal history, delivery information, and newborn records were obtained from chart review.

\subsection{Statistical Analysis}

Bivariate analyses were conducted using chisquare and t-test, as appropriate, to describe the population's demographics, family dynamics, pregnancy complications, and birth outcomes. Logistic regression was used to determine the association between paternal involvement and pregnancy complications/ birth outcomes. Adjusted models accounted for differences in maternal age, maternal education, gravidity, primary household decision-maker and family socioeconomic status. Analysis was completed using IBM SPSS Statistics for Windows, Version 25. ${ }^{14}$

\subsection{Ethical Approval}

This research was conducted in accordance with prevailing ethical principles and reviewed by an Institutional Review Board in both the United States, by the University of South Florida, and in India, by the Human Research Ethics Committee at the Government Medical College of Surat (GMCS) Research staff completed the informed consent process in private, in the participant's preferred language of English, Gujarati, or Hindi. Due to the literacy level of the participants, the survey was administered orally by research staff as an interview in the participant's preferred language. Completed surveys were coded with pseudo-identifiers. A separate list containing pseudo-identifiers and the corresponding patient identifiers was stored securely in an administrative office in the GMCS hospital.

\section{Results}

\section{I. Sociodemographic Characterisitcs Results}

Women who enrolled in the study $(n=404)$ ranged in age from 18 to 35 years $($ mean $=23.54 \pm 3.36)$. The majority of the women were housewives and had less than a secondary school education. More than $40 \%$ reported their in-laws, either mother- or fatherin-law, were the primary decision-makers in their household; however mother-in-laws represented the majority (Table I). Half $(50.0 \%)$ of women surveyed reported high paternal support and a third (33.3\%) reported high paternal attendance. Low paternal support was significantly associated with lower maternal education level whereas low paternal attendance was associated with maternal occupation, family socioeconomic status, gravidity, and the primary decision-maker in the household.

Nearly one-third of pregnancies resulted in a premature birth $(26.7 \%)$ or a low birth weight infant (29.0\%).The most-common pregnancy complications included anemia $(52.0 \%)$, prolonged latent stage labor (I3.9\%), and pre-eclampsia (5.2\%) (Table 2). More than $20 \%$ of the study sample had a history of abortion, $8.9 \%$ had a history of preterm birth, and I I. $4 \%$ had a previous cesarean section.

\subsection{Adverse Birth Outcomes}

Crude logistic regression analysis indicated paternal support and paternal attendance were associated with delivering a low birth weight infant. Women who reported lower partner attendance at prenatal appointments and lower paternal support had two times higher odds of delivering a low birth weight infant after adjusting for maternal age, maternal education, gravidity, primary household decisionmaker and family socioeconomic status (adjusted odds ratio $(A O R)=2.16 ; 95 \%$ Confidence Interval $(\mathrm{Cl}): \mathrm{I} .35-3.47)$ and $\mathrm{AOR}=2.99 ; 95 \% \mathrm{Cl}$ : I.844.86), respectively, compared to their counterparts who reported higher partner attendance and higher partner support. The relationship between paternal support or attendance and preterm birth was not statistically significant (Table 3). Over $40 \%$ of the participants indicated their in-laws, primarily motherin law, as the primary decision-maker and preliminary analysis demonstrated this may be related to low paternal attendance at prenatal appointments.

\section{Discussion}

This study demonstrated a relationship between paternal involvement and low birth weight; however,an association between paternal support or attendance and preterm birth was not apparent in this population. Previous studies have reported associations between absent fathers and higher rates of preterm birth, low birth weight, very low birth weight, and being 
Table I: Population and paternal demographics by paternal support and attendance

\begin{tabular}{|c|c|c|c|c|c|c|c|}
\hline \multirow{2}{*}{$\begin{array}{l}\text { Population } \\
\text { demographics }\end{array}$} & \multirow[t]{2}{*}{ Total N=404 (\%) } & \multicolumn{2}{|c|}{ Paternal support } & \multirow[t]{2}{*}{$\mathbf{p}$} & \multicolumn{2}{|c|}{ Paternal attendance } & \multirow[t]{2}{*}{$\mathbf{p}$} \\
\hline & & High & Low & & High & Low & \\
\hline Mean age (SD) & $23.54 \pm 3.36$ & $23.39 \pm 3.11$ & $23.81 \pm 3.61$ & 0.22 & $23.56 \pm 3.25$ & $23.50 \pm 3.57$ & 0.86 \\
\hline Education & & & & 0.02 & & & 0.49 \\
\hline Illiterate & $54(13.4)$ & $22(11.3)$ & $30(15.3)$ & & $30(11.3)$ & $24(17.6)$ & \\
\hline Primary $\left(\left.\right|^{\text {st }} 8^{\text {th }}\right)$ & $165(40.8)$ & $68(35.1)$ & $91(46.4)$ & & $110(41.4)$ & $55(40.4)$ & \\
\hline Secondary $\left(9^{\text {th }}-10^{\text {th }}\right)$ & $110(27.2)$ & $57(29.4)$ & $49(25.0)$ & & $74(27.8)$ & $36(26.5)$ & \\
\hline Higher $\left(\left.1\right|^{\text {th }}-12^{\text {th }}\right)$ & $47(11.6)$ & $32(16.5)$ & $15(7.7)$ & & $33(12.4)$ & $14(10.3)$ & \\
\hline Bachelor's & $24(5.9)$ & $13(6.7)$ & II (5.6) & & $17(6.4)$ & $7(5.1)$ & \\
\hline Master's & $2(0.5)$ & $2(1.0)$ & $0(0.0)$ & & $2(0.8)$ & $0(0.0)$ & \\
\hline Occupation & & & & 0.47 & & & 0.04 \\
\hline Housewife & $366(91.5)$ & $175(90.7)$ & $181(92.8)$ & & $247(93.9)$ & $119(86.9)$ & \\
\hline Retail & $12(3.0)$ & $9(4.7)$ & $3(1.5)$ & & $5(1.9)$ & $7(5.1)$ & \\
\hline Teacher & $3(0.7)$ & $\mathrm{I}(0.5)$ & $2(1.0)$ & & $0(0.0)$ & $3(2.2)$ & \\
\hline Laborer & $12(3.0)$ & $5(2.6)$ & $5(2.6)$ & & $7(2.7)$ & $5(3.6)$ & \\
\hline Other & $7(1.7)$ & $3(1.6)$ & $4(2.1)$ & & $4(1.5)$ & $3(2.2)$ & \\
\hline SES & & & & 0.15 & & & $>0.01$ \\
\hline Upper & $28(7.1)$ & $18(9.4)$ & $10(5.2)$ & & $23(8.8)$ & $5(3.8)$ & \\
\hline Upper middle & $105(26.7)$ & $56(29.3)$ & $47(24.5)$ & & $78(30.0)$ & $27(20.3)$ & \\
\hline Lower middle & $126(32.1)$ & $58(30.4)$ & $64(33.3)$ & & $83(31.9)$ & $43(32.3)$ & \\
\hline Upper lower & $95(24.2)$ & $37(19.4)$ & $55(28.6)$ & & $61(23.5)$ & $34(25.6)$ & \\
\hline Lower & $39(9.9)$ & $22(11.5)$ & $16(8.3)$ & & $15(5.8)$ & $24(18)$ & \\
\hline Gravidas & & & & 0.99 & & & $>0.01$ \\
\hline Primigravida & $142(35.1)$ & $94(35.2)$ & $48(35.3)$ & & $82(4 \mid .8)$ & $55(28.2)$ & \\
\hline Multigravida & $261(64.6)$ & $173(64.8)$ & $88(64.7)$ & & II 4 (58.2) & I40 (7I.8) & \\
\hline Parity & & & & 1.00 & & & 0.72 \\
\hline Singleton & $395(97.8)$ & 191 (97.9) & $192(98.0)$ & & $260(97.7)$ & $135(98.5)$ & \\
\hline Twins & $8(2)$ & $4(2.1)$ & $4(2.0)$ & & $6(2.3)$ & $2(1.5)$ & \\
\hline Primary decision-maker & & & & 0.36 & & & 0.03 \\
\hline In-laws & $171(42.3)$ & $85(43.8)$ & $77(39.3)$ & & $103(38.9)$ & $68(50.0)$ & \\
\hline Husband, self, equal, other & $230(56.9)$ & $109(56.2)$ & $119(60.7)$ & & $162(61.1)$ & $68(50.0)$ & \\
\hline Paternal education & & & & 0.11 & & & 0.19 \\
\hline Illiterate & $58(14.4)$ & $25(12.9)$ & $32(16.4)$ & & 31 (II.7) & 27 (19.9) & \\
\hline Primary $\left(\left.\right|^{\text {st }}-8^{\text {th }}\right)$ & $140(34.7)$ & $62(32.0)$ & $74(37.9)$ & & $96(36.2)$ & $44(32.4)$ & \\
\hline Secondary $\left(9^{\text {th }}-10^{\text {th }}\right)$ & $112(27.7)$ & $54(27.8)$ & $53(27.2)$ & & $71(26.8)$ & $4 I(30 . I)$ & \\
\hline Higher $\left(\left.1\right|^{\mathrm{th}}-12^{\mathrm{th}}\right)$ & $55(\mid 3.6)$ & $34(17.5)$ & $19(9.7)$ & & 40 (I5.I) & $15(11.0)$ & \\
\hline Bachelor's & $30(7.4)$ & $14(7.2)$ & $16(8.2)$ & & $23(8.7)$ & $7(5.1)$ & \\
\hline Master's & $6(1.5)$ & $5(2.6)$ & I (0.5) & & $4(1.5)$ & $2(1.5)$ & \\
\hline
\end{tabular}

small for gestational age. ${ }^{15}$ This study contributes to the literature by examining this relationship in an international context and exploring socio-cultural implications in-laws may have on paternal involvement, taking into account a different cultural dynamic. Over
$40 \%$ of the participants indicated their in-laws as the primary decision-maker, and preliminary analysis demonstrated this may be related to low paternal attendance at prenatal appointments. However, additional research is needed to adequately explore 
Table 2: Maternal complications in population per paternal involvement

\begin{tabular}{|c|c|c|c|c|c|c|c|}
\hline \multirow[t]{2}{*}{ Complications } & \multirow{2}{*}{$\frac{(\mathrm{N}=350) \mathrm{N}(\%)}{\text { Total }}$} & \multicolumn{2}{|c|}{ Paternal support } & \multirow[t]{2}{*}{$\mathbf{p}$} & \multicolumn{2}{|c|}{ Paternal attendance } & \multirow[t]{2}{*}{$\mathbf{p}$} \\
\hline & & High & Low & & High & Low & \\
\hline Anemia & $212(52.5)$ & $102(52.0)$ & $106(54.1)$ & 0.69 & $139(52.1)$ & $73(53.3)$ & 0.82 \\
\hline Preterm birth & $108(26.7)$ & $59(55.1)$ & $48(44.9)$ & 0.26 & $68(26.0)$ & $40(37.0)$ & 0.36 \\
\hline Low birth weight & $117(29.0)$ & $39(33.9)$ & $76(66.1)$ & $>0.01$ & $64(54.7)$ & $53(45.3)$ & $>0.01$ \\
\hline History of preterm & $36(8.9)$ & $23(35.4)$ & $13(32.5)$ & 0.76 & $22(31.0)$ & $14(36.8)$ & 0.54 \\
\hline History of abortion & $85(21.0)$ & $4 \mid(2 \mid .8)$ & $43(22.6)$ & 0.85 & $50(19.4)$ & $35(26.7)$ & 0.10 \\
\hline Prolonged-latent stage labor & $56(13.9)$ & $39(19.9)$ & $13(6.6)$ & $>0.01$ & $36(13.5)$ & $20(14.6)$ & 0.76 \\
\hline Previous cesarean section & $46(11.4)$ & $18(9.2)$ & $27(13.8)$ & 0.15 & $33(12.4)$ & $13(9.5)$ & 0.39 \\
\hline Abdominal pain w/ cramping & $40(9.9)$ & $28(14.3)$ & II (5.6) & $>0.01$ & $28(10.5)$ & $12(8.8)$ & 0.58 \\
\hline Pre-eclampsia & $21(5.2)$ & $9(4.6)$ & $12(6.1)$ & 0.50 & $9(3.4)$ & $12(8.8)$ & 0.02 \\
\hline Eclampsia & $5(1.2)$ & $3(1.5)$ & $\mathrm{I}(0.5)$ & 0.32 & $2(0.7)$ & $3(2.2)$ & 0.22 \\
\hline Gestational diabetes mellitus & $4(1.0)$ & $3(1.5)$ & $\mathrm{I}(0.5)$ & 0.32 & $2(0.7)$ & $2(1.5)$ & 0.50 \\
\hline Placenta previa & $5(1.2)$ & $3(1.1)$ & $2(1.5)$ & 0.77 & $2(1.0)$ & $3(1.5)$ & 0.65 \\
\hline Fetal respiratory distress & $14(3.5)$ & $6(3.1)$ & $8(4.1)$ & 0.59 & $7(2.6)$ & $7(5.1)$ & 0.20 \\
\hline NICU admission for jaundice & $9(2.2)$ & $4(2.0)$ & $5(2.6)$ & 0.74 & $4(1.5)$ & $5(3.6)$ & 0.17 \\
\hline
\end{tabular}

Table 3:Relationship between paternal involvement and low birth weight/ preterm birth

\begin{tabular}{|c|c|c|c|c|}
\hline \multirow[t]{2}{*}{ Paternal involvement } & \multicolumn{2}{|c|}{ Low birth weight } & \multicolumn{2}{|c|}{ Preterm birth } \\
\hline & $\begin{array}{l}\text { Crude odds ratio } \\
\qquad(95 \% \mathrm{CI})\end{array}$ & $\begin{array}{l}\text { Adjusted* odds ratio } \\
\qquad(95 \% \mathrm{CI})\end{array}$ & $\begin{array}{l}\text { Crude odds ratio } \\
\qquad(95 \% \mathrm{Cl})\end{array}$ & $\begin{array}{c}\text { Adjusted* odds ratio } \\
(95 \% \mathrm{Cl})\end{array}$ \\
\hline Low paternal support & $2.56(1.62-4.02)$ & $2.99(1.84-4.86)$ & $0.77(0.49-1.21)$ & $0.84(0.52-I .35)$ \\
\hline Low paternal attendance & 2.15 (1.27-3.09) & $2.16(1.35-3.47)$ & I.24 (0.78-I.97) & $1.28(0.83-2.23)$ \\
\hline
\end{tabular}

*Models adjusted for maternal age, maternal education, gravidity, primary decisionmaker, and household SES

the influence of in-laws' decision-making on paternal involvement.

Limitations of this study include potential underreporting of less acute pregnancy complications and omission of pertinent prenatal care information including risk factors such as smoking, substance use and maternal pre-pregnancy BMI.Additionally, antenatal support and attendance were reported during the postpartum period, requiring mothers to recall levels of support. Furthermore, the participants' husbands were not interviewed. However, a strength of this study is that outcome data (e.g., birth weight, gestational age at delivery) were extracted directly from the patient's prenatal medical records, therefore minimizing the potential for recall bias in outcome measurements.

Future studies should consider prenatal enrolment and interviews with fathers to assess their perceptions of their involvement during pregnancy.

\section{Conclusion and Global Health Implications}

Low paternal support during pregnancy may be a missed opportunity to increase healthy practices as well as decrease the risks associated with limited social support during pregnancy. It is important to consider varying socio-cultural family dynamics in different populations and how they may influence paternal involvement during pregnancy.

\section{Compliance with Ethical Standards}

Conflicts of Interest: There are no conflicts of interest to disclose regarding this study. Financial Disclosure: There are no financial disclosures regarding this study. Funding/Support: The authors thank the Government Medical College New Civil Hospital, Surat, India for allowing them to conduct the study, and the University of South Florida College 
of Public Health and the Departments of Obstetrics and Gynecology and Preventative and Social Medicine, Community Medicine at New Civil Hospital for supporting the research. This research was funded by an award from the Scholarly Concentrations Program at the University of South Florida Health Sciences, Morsani College of Medicine. Ethics Approval: This study was reviewed by the Institutional Review Board at University of South Florida and by the Human Research Ethics Committee at the Government Medical College of Surat, India.

\section{Key Messages}

- Absence of paternal support during pregnancy might be a missed opportunity to increase healthful practices during pregnancy and decrease some of the risks associated with chronic to moderate stress during pregnancy.

- Socio-cultural family dynamics in different populations may influence paternal involvement which may subsequently influence birth outcomes.

- Additional research is needed to adequately explore the influence of in-laws decision-making and paternal involvement.

\section{References}

I. IIPS and ICF. National Family Health Survey (NFHS-4),2015-16, India. Mumbai: International Institute for Population Sciences (IIPS); 2017.

2. The World Bank. Infant Mortality. https://data. worldbank.org/indicator/SP.DYN.IMRT.IN Accessed 27 January 2020.

3. Alio AP, Salihu HM, Mclntosh C, et al. The effect of paternal age on fetal birth outcomes. Am J Mens Health. 20I 2;6(5):427-435.

4. Padilla YC, Reichman NE. Low birthweight: Do unwed fathers help? Child Youth Serv Rev. 200 I;23(4-5):427-452.

5. Ghosh JKC, Wilhelm MH, Dunkel-Schetter C, Lombardi CA, Ritz BR. Paternal support and preterm birth, and the moderation of effects of chronic stress: a study in Los Angeles County mothers. Arch Womens Ment Health. 2010; I3(4):327-338.

6. Kumar G, Choudhary TS, Srivastava A, et al. Utilisation, equity and determinants of full antenatal care in India:analysis from the National Family Health Survey 4. BMC Pregnancy Childbirth. 2019;19(I):327.

7. Comrie-Thomson L, Tokhi M, Ampt F, et al. Challenging gender inequity through male involvement in maternal and newborn health: critical assessment of an emerging evidence base. Cult Health Sex. 2015;17 Suppl 2:SI77-189.

8. Suppal P, Roopnarine JL. Paternal involvement in child care as a function of maternal employment in nuclear and extended families in India. Sex Roles. 1999;40(9-10):731-744.

9. Rew M, Gangoli G, Gill AK. Violence between female in-laws in India.J Int Womens Stud. 2013; I4(I): 147-160.

10. Takegata M, Ohashi Y, Lazarus A, Kitamura T. Crossnational differences in psychosocial factors of perinatal depression: A systematic review of India and japan. Healthcare (Basel). 2017;5:pii: E9I.

II. Silverman JG, Balaiah D, Decker MR, et al. Family Violence and Maltreatment of Women During the Perinatal Period: Associations with Infant Morbidity in Indian Slum Communities. Matern Child Health J. 2016;20(I):149-157.

12. Chadda RK, Deb KS. Indian family systems, collectivistic society and psychotherapy. Indian J Psychiatry. 2013;55(Suppl 2):S299-S309. doi:10.4103/0019-5545.105555

13. Straughen JK, Caldwell CH, Young AA, Jr., Misra DP. Partner support in a cohort of African American families and its influence on pregnancy outcomes and prenatal health behaviors. BMC Pregnancy Childbirth. 2013;13(1):187.

14. IBM SPSS Statistics (forWindows)[computer program]. Version 25.0.Armonk, NY; IBM SPSS Corp; 2017.

15. Alio AP, Kornosky JL, Mbah AK, Marty PJ, Salihu HM. The impact of paternal involvement on feto-infant morbidity among Whites, Blacks and Hispanics. Matern Child Health J. 20 I0; 14(5):735-74I. 